\title{
CONNFIGURAÇÕES DOS VALORES PESSOAIS E DAS CARACTERÍSTICAS DOS EMPREENDEDORES SOCIAIS EM ORGANIZAÇÕES SOCIAIS BRASILEIRAS E PORTUGUESAS
}

\author{
CONFIGURATIONS OF PERSONAL VALUES AND SOCIAL \\ ENTREPRENEURS CHARACTERISTICS IN PORTUGUESE AND \\ BRAZILIAN SOCIAL ORGANIZATIONS
}

\section{Leticia Lengler}

Doutora em Administração pela Universidade Federal de Santa Maria (Santa Maria/Brasil).

Professora na Universidade Federal de Santa Maria (Santa Maria/Brasil).

E-mail: leticia.lengler@ufsm.br

\section{Vania de Fátima Barros Estivalete}

Pós-Doutora em Sociologia Econômica das Organizações pelo Instituto Superior de Economia e Gestão da Universidade de Lisboa (Lisboa/Portugal). Professora na Universidade Federal de Santa Maria (Santa Maria/Brasil).

E-mail: vaniaestivalete@ufsm.br 


\section{RESUMO}

Com o objetivo de analisar como se configuram os valores pessoais e as características dos empreendedores sociais em organizações sociais brasileiras e portuguesas do setor da educação, realizou-se uma pesquisa qualitativa de caráter exploratório e descritivo com três empreendedores sociais no Brasil e três em Portugal. Para o tratamento dos dados utilizou-se a técnica de análise de conteúdo, com transcrições de entrevistas e observação direta. As evidências convergem para aspectos semelhantes entre os dois países, com a manifestação de interesses coletivos por meio da valorização da benevolência e do universalismo. Dentre as características convergentes, destaca-se ainda que os pesquisados possuem foco para o valor social e almejam criar valor social ao desenvolverem suas atividades com o propósito de transformação da sociedade em um lugar melhor. Dessa forma, é relevante refletir que o altruísmo manifestado nos relatos dos empreendedores sociais pesquisados sugere uma aproximação entre a missão social e os valores pessoais, sugestionando uma configuração favorável para a criação de valor social e para o empoderamento das pessoas que empreendem e atuam em prol do impacto social.

Palavras-chave: Valores Pessoais. Características dos Empreendedores Sociais. Organizações Sociais.

\section{ABSTRACT}

Aiming to analyze how personal values and social entrepreneurship characteristics set a configuration in Brazilian and Portuguese social organizations in the education sector, a qualitative exploratory and descriptive research was conducted with three social entrepreneurs from Brazil, and three from Portugal. For data treatment, the technique of content analysis was used, with interview transcripts and direct observation. The evidence converges to similar aspects between the two countries, with the expression of collective interests through the valorization of benevolence and universalism. Among the convergent characteristics, it is highlighted that the interviewees have a focus on social value and aim to create social value by developing their activities with the purpose of transforming society into a better place. Thus, it is relevant to reflect that the altruism manifested in the reports of the social entrepreneurs surveyed, suggests an approximation between the social mission and personal values, suggesting a favorable configuration for the creation of social value, and for the empowerment of people who undertake and act in favor of social impact.

Keywords: Personal Values. Social Entrepreneurs' Characteristics. Social Organizations. 


\section{INTRODUÇÃO}

O empreendedorismo social constitui-se em um tema emergente no ambiente acadêmico e organizacional, com relativo destaque para os empreendedores sociais, que são identificados por Roundy (2017) como players que podem ter um papel ainda maior por criar organizações sociais capazes de estimular o ecossistema do empreendedorismo social. É pertinente ressaltar que este estudo se apoia no estudo seminal de Dees (1998), ao destacar que o propósito dos empreendedores sociais não é apenas a criação de riqueza, mas a principal missão desses indivíduos é criar valor social. Assim, temse o entendimento que o empreendedor social é o principal agente de mudanças sociais. Acredita-se que esse entendimento é consistente com definições defendidas por outros acadêmicos (DEES, 2007; AUSTIN et al., 2006; ZHARA et al. 2009) e instituições do segmento, como por exemplo Ashoka, Fundação Schwab e Babson College, sendo esta última uma das responsáveis por liderar pesquisas globais sobre o empreendedorismo e os empreendedores sociais (GEM SOCIAL, 2016).

Segundo o levantamento da rede de empreendedores de países em desenvolvimento Aspen Network of Development Entrepreneurs, os negócios sociais têm movimentado cerca de 60 bilhões de dólares em nivel global (ANDE, 2018). Para exemplificar esse crescimento de iniciativas de empreendedores sociais, identifica-se que mais de 3,2\% da população adulta mundial está envolvida na criação de um negócio de impacto, enquanto em Portugal essa porcentagem é de 13,4\% (GEM SOCIAL, 2016). No contexto da América Latina, o Brasil representa o segundo maior mercado de negócios de impacto social, sendo que os maiores investimentos são na área da educação, inclusão financeira e saúde (ANDE, 2018).

Como háum vasto número de fatores capazes de interferirnapredisposição parao empreendedorismo social, além de incluir o conjunto de características individuais dos empreendedores, que foi foco dos estudos sobre o empreendedorismo social até a metade desse novo século (LEADBEATER, 1997; DRAYTON, 2002; MAIR; MARTI, 2006; DACIN et al., 2010), esta pesquisa diferencia-se por englobar os valores pessoais, uma vez que estes podem ser considerados como catalisadores do empreendedorismo social (HEMINGWAY, 2005). Isto é respaldado por Schwartz (2003), que discute os tipos de valores pessoais em relação aos tipos motivacionais. Acrescenta-se a isso os apontamentos de Holt (1997), que indicam diferenças nos sistemas de valores dos empreendedores chineses e americanos, principalmente em relação aos chineses manifestarem o individualismo de forma pouco expressiva, indicando um senso de coletivismo mais desenvolvido.

Este estudo adota a perspectiva de que os valores voltados para o coletivismo e de responsabilidade com a sociedade - em oposição à orientação individualista, representam um campo fértil que pode ser aplicado aos empreendedores sociais trazendo benefícios para a sociedade (HEMINGWAY, 2005). Portanto, 
surge o seguinte questionamento: Como os valores pessoais e as características dos empreendedores sociais se configuram nos empreendimentos sociais? A partir deste questionamento, desenvolveu-se a proposição desta pesquisa com o objetivo de analisar as configurações dos valores pessoais e das características dos empreendedores sociais em organizações sociais brasileiras e portuguesas do setor da educação.

Para alcançar os objetivos propostos, a construção deste estudo está pautada no aporte teórico que aborda os Valores Pessoais, sob a perspectiva de Schwartz (1993), e nas principais características discutidas pelos pesquisadores que se debruçaram a estudar os empreendedores sociais. Com relação aos aspectos metodológicos destaca-se que este é um estudo qualitativo que contempla a etapa exploratória e a descritiva, na qual foram empregadas entrevistas semiestruturadas realizadas com empreendedores sociais de seis organizações sociais (três do Brasil e três de Portugal). A partir disto, utilizou-se a análise de conteúdo, como técnica para apresentar, analisar e discutir os temas envolvidos que culminaram nas principais reflexões de pesquisa, que são apresentadas nas próximas seções.

\section{VALORES PESSOAIS}

Hemingway (2005), com base em Schwartz e Blinsky (1987), propôs que os valores pessoais são catalisadores do empreendedorismo social, no qual os valores dominantes com foco no senso de coletivismo e responsabilidade com a sociedade - em oposição à orientação individualista, podem ser aplicados aos empreendedores sociais. De acordo com a proposição da autora, os empreendedores sociais estão motivados para uma agenda social focando não só na sua função enquanto indivíduo, mas também no âmbito social em relação aos benefícios que o mesmo pode promover, visando soluções para os problemas sociais.

As pesquisas realizadas por Schwartz $(1992,2003)$ servem como referência para os pesquisadores no campo de valores pessoais, sendo que os valores pessoais correspondem a representações cognitivas de três exigências humanas universais: necessidades biológicas do indivíduo, necessidades sociais de interação, necessidades sociais institucionais de sobrevivência e bem-estar dos grupos (SCHWARTZ; BILSKY,1987; SCHWARTZ, 1992). Com base nessas exigências, Schwartz (1992, 2003) desenvolveu a Teoria dos Valores que identificam os tipos motivacionais com suas respectivas características e valores, conforme conta no quadro 1. 
Quadro 1 - Tipos motivacionais de Schwartz

\begin{tabular}{|l|l|l|}
\hline \multicolumn{1}{|c|}{ Tipos } & \multicolumn{1}{|c|}{ Características } & \multicolumn{1}{c|}{ Valores } \\
\hline Autodeterminação & $\begin{array}{l}\text { Pensamento e ação independente, criatividade, } \\
\text { liberdade e escolha de objetivos próprios. }\end{array}$ & $\begin{array}{l}\text { Curiosidade, criatividade, liberdade, escolha, } \\
\text { respeito próprio. }\end{array}$ \\
\hline Estimulação & Excitação, novidade, desafio na vida. & Audacioso, vida variada, vida excitante. \\
\hline Hedonismo & Prazer ou gratificação. & Prazer, vida de prazer, aproveita a vida. \\
\hline Realização & $\begin{array}{l}\text { Sucesso pessoal por meio da demonstração de } \\
\text { competência conforme padrões sociais. }\end{array}$ & $\begin{array}{l}\text { Bem-sucedido, capaz, influente, inteligente, } \\
\text { esperto, ambicioso. }\end{array}$ \\
\hline Poder & $\begin{array}{l}\text { Status social e prestígio, controle ou domínio sobre } \\
\text { pessoas e recursos. }\end{array}$ & $\begin{array}{l}\text { oder social, autoridade, preservador de imagem } \\
\text { pública, reconhecimento social. }\end{array}$ \\
\hline Segurança & $\begin{array}{l}\text { Segurança, harmonia e estabilidade da sociedade, } \\
\text { relacionamentos e de si mesmo. }\end{array}$ & $\begin{array}{l}\text { Segurança nacional, ordem social, segurança da } \\
\text { família, senso de pertencer. }\end{array}$ \\
\hline Conformidade & $\begin{array}{l}\text { Obediência, restrição de ações, inclinações a não } \\
\text { violar expectativas ou normas sociais. }\end{array}$ & $\begin{array}{l}\text { Obediente, respeito aos idosos e pais, } \\
\text { autodisciplina, polidez. }\end{array}$ \\
\hline Tradição & $\begin{array}{l}\text { Respeito, compromisso e aceitação dos costumes } \\
\text { da sociedade. }\end{array}$ & $\begin{array}{l}\text { Ciente dos limites, respeito à tradição, moderado. } \\
\text { Benevolência }\end{array}$ \\
\hline Preservar e fortalecer o bem-estar de pessoas. & $\begin{array}{l}\text { Prestativo, leal, amizade verdadeira, vida } \\
\text { espiritual, vida com sentido. }\end{array}$ \\
\hline
\end{tabular}

Fonte: Baseado em Schwartz (1992, 2003).

Os dez tipos motivacionais de valores apontados por Schwartz $(1992,2003)$ no Quadro 1 incluem os valores básicos reconhecidos em culturas do mundo todo, sendo estes organizados em 4 dimensões: (i) abertura à mudança, que envolve os valores autodeterminação, estimulação e hedonismo; (ii) conservação, que é constituída pelos valores segurança, conformidade e tradição; (iii) autopromoção, que envolve os valores poder, realização e hedonismo; e (iv) autotranscendência, que abrange os valores universalismo e benevolência. Tais dimensões são explicadas como um aspecto estrutural que consiste nas relações de dinâmicas que ocorre entre esses valores, podendo os mesmos serem conflitantes ou congruentes.

Schwartz $(1992,2003,2006)$ identifica as dimensões como bipolares, sendo que a (i) abertura à mudança contrasta com os valores da (ii) conservação. Esta dimensão explica a relação conflitante da ação e pensamento independente (autodeterminação e estimulação) versus práticas tradicionais de preservação e proteção da estabilidade (segurança, conformidade e tradição). Assim, quanto mais afastados os valores estiverem em qualquer uma das direções ao redor do círculo mais desfavoráveis são suas motivações subjacentes, podendo gerar grande conflito se situadas em posição oposta (SCHWARTZ, 
1992, 2006). É possivel perceber também que quanto mais contíguo os valores estiverem mais similares são suas motivações subjacentes, ou seja, quanto mais próximos dois valores estiverem ao longo do círculo, que é considerado como um continuum motivacional, mais similares serão as suas motivações, e quanto mais distantes mais antagônicas. Por exemplo, de acordo com Schwartz (1992), as ações que possuem a intenção de obediência e manifestam o valor Conformidade (quadrante da Conservação) parecem conflitar com as ações em busca da independência que expressam o valor Autodeterminação (quadrante da Abertura à Mudança), mas elas são compatíveis com as ações que promovem a Segurança e a Tradição.

Os estudos de Schwartz (1992) revelaram, ainda, que cinco motivações de valores servem a interesses individuais e não têm preocupação com o bem-estar do outro e com a natureza (hedonismo, realização, poder, estimulação e autodeterminação) opondo-se a outros três tipos motivacionais (benevolência, tradição e conformidade) que servem a interesses coletivos. Com esta dinâmica, Schwartz (1992) sinalizou a existência das motivações compativeis ao considerar que o valor de Realização foi reforçado pelas ações em busca de destaque de uma posição social ou de autoridade (Poder) em relação aos outros indivíduos. 0 autor também identificou fortes evidências de conflito de valores que demonstraram preocupação com o bem-estar dos outros e com a demonstração de presteza (Benevolência), ao mesmo tempo em que esses indivíduos estavam em busca do sucesso pessoal (Realização).

Em complemento, Melo Neto e Fróes (2002) explicam que no contexto do empreendedorismo social a ação individual reconstrói-se no coletivo, partindo da constatação de que os empreendedores sociais criam negócios e oportunidades, transformando não apenas a sua realidade, mas causando um impacto na qualidade de vida das pessoas beneficiadas com a proposta do projeto social em que estão inseridos. $\mathrm{Na}$ visão dos autores, isto pode ser obtido especialmente por meio do envolvimento dos membros da comunidade, por meio da participação, integração e desenvolvimento coletivo. Assim, os valores pessoais podem ser considerados como fatores influenciadores do comportamento dos indivíduos, podendo estes estarem voltados tanto para objetivos individuais como coletivos.

Nos últimos anos, multiplicaram-se as pesquisas sobre a relação dos valores pessoais com características, atributos, atitudes e comportamentos manifestados em diversas áreas da gestão (BANERJEE, 2004; BHATTA, 2004; ENGELMAN, et al., 2015; KIRKLEY, 2016; SOTIROPOULOU et al., 2019). Ao estudar os empreendedores sociais, Kirkley (2016) também identificou que os valores podem ser observados por meio de comportamentos que expressam a preocupação do indivíduo com o âmbito social. 


\section{CARACTERÍSTICAS DOS EMPREENDEDORES SOCIAIS}

Dacin et al. (2011) alertam que muitos estudos empíricos alimentam o debate acadêmico sobre as características heroicas dos empreendedores sociais capazes de mudar o mundo. Aproximando-se dessa discussão, outros críticos (COOK et al., 2001; NICHOLLS, CHO, 2008; NICHOLLS, 2011; CASAQUI, 2015) também se manifestam opondo-se à corrente dominante da literatura que glorifica o indivíduo empreendedor, pois o empreendedor social não possui o papel heroico de resolver todos os problemas sociais existentes (AUERSWALD, 2009). Ao reconhecer essas correntes, para a realização desta pesquisa adotou-se o entendimento de que o empreendedor social é o principal agente de mudanças sociais.

A literatura (MAIR; MARTI, 2006; DACIN, 2010; ENGELMAN et al., 2015) aponta que há dois tipos de empreendedorismo distintos, o comercial e o social, mas há um certo consenso entre os estudiosos (SHAW; CARTER, 2007; AUSTIN et al., 2006) quanto às semelhanças entre esses dois tipos de empreendedores. Alguns autores argumentam ainda, que os empreendedores sociais possuem uma tarefa mais complexa e trabalham num ambiente também mais complexo que os empreendedores comerciais (DEES, 1998; HAYWARD et al., 2006; AUSTIN et al., 2006; MAIR; MARTI, 2006; SHAW; CARTER, 2007). Bornstein e Davis (2010) salientam que o que diferencia os empreendedores sociais dos comerciais, sejam eles homens ou mulheres, não são as habilidades específicas como persistência e confiança, mas a determinação deles em alcançar, em longo prazo, os objetivos sociais que eles acreditam.

Ao revisar os principais pesquisadores, identifica-se que empreendedores sociais são caracterizados como indivíduos visionários, dirigidos por uma visão social com habilidade para ver o mundo de uma forma diferente (BORNSTEIN; DAVIS, 2010), em busca de oportunidades para se tornarem agentes de mudança social (LEADBEATER, 1997; HEMINGWAY, 2005; AUSTIN et al., 2006; ZAHRA et al., 2009).

Para cada autor, o empreendedor social compreende um grupo de características distintas e os estudos não apontam uma concordância de todos os autores em relação à essas características, conforme discussões de Engelman et al. (2015). Assim, a elaboração do quadro 2 oferece diferentes evidências sobre as principais características dos empreendedores sociais citadas na literatura. 
Quadro 2 - Características dos empreendedores sociais

\begin{tabular}{|c|c|}
\hline EMPREENDEDORES SOCIAIS & AUTORES \\
\hline Pró - ativos e apaixonados & $\begin{array}{l}\text { Steinerowski et al., 2008; Ashton, 2010; Bornstain e Davis, 2010; Dacin } \\
\text { et al., } 2010 .\end{array}$ \\
\hline Inovadores & Leadbeater, 1997; Dees, 1998; Drayton, 2002, Steinerowski et al., 2008. \\
\hline Buscam oportunidades sociais & $\begin{array}{l}\text { Leadbeater, 1997; Hemingway, 2005; Austin et al., 2006; Peredo e } \\
\text { McLean, 2006; Zahra et al., } 2009 .\end{array}$ \\
\hline $\begin{array}{l}\text { Visionários (possuem foco na visão para gerar } \\
\text { valor social) }\end{array}$ & $\begin{array}{l}\text { Austin et al., 2006; Steinerowski et al., 2008; Dacin et al., 2010; Bornstein } \\
\text { e Davis, 2010; Mair e Marti, } 2006 .\end{array}$ \\
\hline Criativos & $\begin{array}{l}\text { Leadbeater,1997; Drayton, 2002; Hemingway, 2005; Mair e Marti, 2006; } \\
\text { Martin e Osberg, } 2007 .\end{array}$ \\
\hline $\begin{array}{l}\text { Orientados para uma missão social } \\
\text { (almejam criar valor social) }\end{array}$ & $\begin{array}{l}\text { Leadbeater,1997; Dees, 1998; Hemingway, 2005; Austin et al., 2006; } \\
\text { Mair e Marti, 2006; Zahra et al., 2009; Dacin et al., } 2010 .\end{array}$ \\
\hline $\begin{array}{l}\text { Interconectados com o ecossistema global } \\
\text { (sustentabilidade) }\end{array}$ & Drayton, 2002; Melo Neto e Froes, 2002. \\
\hline Capacidade de assumir riscos & $\begin{array}{l}\text { Leadbeater,1997; Hemingway, 2005; Mair e Marti, 2006; Martin e } \\
\text { Osberg, 2007. }\end{array}$ \\
\hline $\begin{array}{l}\text { Foco no capital humano (habilidade em lidar com } \\
\text { as pessoas) }\end{array}$ & Austin et al., 2006; Bornstein e Davis, 2010. \\
\hline Capacidade gerenciar recursos financeiros & Leadbeater, 1997; Austin et al., 2006; Peredo e McLean, 2006. \\
\hline $\begin{array}{l}\text { Engajados por terem vivido uma experiência } \\
\text { prévia com foco no valor social }\end{array}$ & $\begin{array}{l}\text { Barendsen e Gardener, 2004; London e Morfopoulos, 2010; Obschonka } \\
\text { et al., } 2010 .\end{array}$ \\
\hline
\end{tabular}

\section{Fonte: Elaborado pelos autores.}

Segundo o quadro 2, pode-se compreender que os empreendedores sociais possuem habilidade para recrutar e motivar outros indivíduos para a sua causa e constroem redes de pessoas essenciais para alcançar seus objetivos (AUSTIN, et al., 2006; BORNSTEIN; DAVIS; 2010), eles são pessoas apaixonadas e proativas (MARTIN; OSBERG, 2007; STEINEROWSKI et al., 2008; ASHTON, 2010; BORNSTEIN; DAVIS, 2010; DACIN, et al., 2010), são persistentes e firmes pois precisam levar suas soluções criativas adiante (DEES, 2007; MARTIN; OSBERG, 2007; STEINEROWSKI et al., 2008), encontrando formas criativas para driblar as barreiras e os desafios que se interpõem ao longo do caminho. Eles são inovadores (LEADBEATER, 1997; DEES, 2007; DRAYTON, 2002; STEINEROWSKI et al., 2008; LONDON; MORFOPOULOS, 2010) e orientados para os riscos financeiros, para competirem por escassos recursos para gerar retornos econômicos (LEADBEATER, 1997; HEMINGWAY, 2005; PEREDO; McLEAN, 2006). Barendser e Gardner (2004) destacam que os empreendedores sociais recebem ainda influência do meio em que estão 
inseridos por meio de suas experiências pessoais e profissionais, sendo engajados e motivados pelas causas sociais.

Para a maioria dos pesquisadores, os empreendedores sociais possuem uma característica peculiar de trabalhar em prol de realizar sua missão social (LEADBEATER,1997; DEES, 1998; HEMINGWAY, 2005; AUSTIN et al., 2006; MAIR; MARTI, 2006; NICHOOLS, CHO, 2008; ZAHRA et al., 2009; DACIN et al., 2010). Porém, cabe ressaltar que a literatura também apresenta críticas com relação ao discurso globalizado que atribui certo grau de heroísmo aos empreendedores sociais.

Para Mello (2016) as contradições nos negócios sociais e a utilização do discurso empreendedor para legitimar suas ações acabam dificultando uma análise da real intenção e impacto de tais empreendimentos. Tendo em vista esta ressalva, destaca-se que discutir como se configuram as características dos empreendedores sociais não é uma intenção de exaltação dos aspectos positivos ou negativos desses indivíduos, mas sim oferecer uma possibilidade de compreensão de que tais características podem se aproximar dos valores pessoais que os empreendedores sociais carregam.

A partir desta discussão, os pressupostos construídos para esta pesquisa consideram que: 1) as características dos empreendedores sociais podem se relacionar com os valores pessoais com foco no coletivo, e 2) os valores pessoais e as características dos empreendedores sociais configuram-se no desenvolvimento das atividades das organizações sociais. A partir disto, este estudo foi construído considerando as dimensões de análise que se referem aos valores pessoais e às características dos empreendedores sociais, conforme destaca-se na seção a seguir.

\section{METODOLOGIA}

No intuito de alcançar o objetivo a que esta pesquisa se propõe, em busca de "analisar as configurações dos valores pessoais e das características dos empreendedores sociais em organizações sociais brasileiras e portuguesas do setor da educação", optou-se pela realização de uma pesquisa de natureza qualitativa. As abordagens qualitativas são peculiarmente úteis em áreas que não estão muito desenvolvidas teoricamente (EDMONDSON; MCMANUS, 2007), o que se revela particularmente pertinente neste estudo, considerando a perspectiva comportamental dos empreendedores sociais pesquisados.

Esta pesquisa possui caráter exploratório e descritivo, sendo que a etapa exploratória foi pautada na proposta de Marconi e Lakatos (2010). Para esta etapa, optou-se pela utilização de entrevistas semiestruturadas realizadas com empreendedores sociais de seis organizações sociais (três do Brasil e três de Portugal). A partir disto, a etapa descritiva foi empregada utilizando-se a observação direta. Para que se tenha um instrumento válido e fidedigno de investigação científica Lüdtke e André (1986) alertam 
que a observação precisa ser sistemática, o que implicou na elaboração de um planejamento que gerou um Protocolo de Observação, para o observador guiar-se por um roteiro alinhado aos objetivos da pesquisa.

Quanto ao método, considerou-se que esta pesquisa segue a estrutura de estudo de casos múltiplos (YIN, 2016). A partir das recomendações de Yin (2016) elaborou-se um Protocolo de Estudo de Casos, que segundo o autor é essencial para apontar a visão geral do caso. Para escolha das unidades de análise que integram esta pesquisa, partiu-se do critério de reconhecimento e relevância que os empreendedores sociais possuem, ao receberem destaque pelas suas contribuições sociais na área da educação. No contexto do Brasil, utilizou-se o catálogo da Fundação Schwab (2018) e em Portugal o catálogo do Institute for Social Entrepreneurship da Social Business School - IES, que auxilia o desenvolvimento de iniciativas inovadoras no contexto do empreendedorismo social europeu (PARENTE, 2014). Para preservar o sigilo e confidencialidade dos dados, os empreendedores sociais e as organizações sociais elencadas neste estudo foram identificadas por códigos, utilizando-se OB1, OB2 e OB3, para as organizações brasileiras e OP1, OP2 e OP3 para as organizações portuguesas. Os empreendedores sociais das respectivas organizações sociais foram codificados da seguinte forma: EOB1, EOB2, EOB3, EOP1, EOP2 e EOP3.

Para a coleta dos dados foi realizado um roteiro de entrevista semiestruturado, contendo uma seção sobre o perfil dos entrevistados e outra relacionada aos Valores Pessoais e Características dos Empreendedores Sociais. No intuito de responder a questão central de pesquisa foi definido o contexto de análise utilizando-se as categorias de análise levantadas no referencial teórico (Quadro 1 e Quadro 2).

Como estratégia para a análise de dados utilizou-se a análise de conteúdo com a categorização temática (BARDIN, 2015), que prevê três fases fundamentais denominadas: 1) pré-análise, 2) exploração do material, e 3) tratamento dos resultados com interpretação inferencial. A fase de pré-análise permitiu tomar contato exaustivo com o texto proveniente das falas transcritas e do material coletado durante a pesquisa com o objetivo de sistematizar as ideias iniciais discutidas no referencial teórico tendo em vista a transcrição das entrevistas com os empreendedores sociais do Brasil e de Portugal, a organização dos documentos coletados junto às organizações Brasileiras e Portuguesas e a triagem das evidências observacionais. Concluída esta fase, passou-se para a exploração do material, que consiste na construção das operações procurando codificar os elementos de análise por temas. Realizou-se uma análise aprofundada dos materiais identificados, e a partir disto foram elaborados quadros de referências, com identificação dos elementos e categorias. Por fim, a última etapa que envolve a interpretação inferencial ou tratamento dos resultados obtidos (BARDIN, 2015), compreendeu a análise qualitativa e a verificação da homogeneidade e heterogeneidade de percepções dos entrevistados (MARTINS; LINTZ, 2000). 


\section{ANÁLISE E DISCUSSÃO DOS RESUTADOS}

Os seis empreendedores sociais e as respectivas organizações em que atuam foram analisadas, apresentando as características referentes ao perfil dos empreendedores sociais e as categorias analíticas do estudo. Os dados referentes ao perfil dos empreendedores sociais investigados são apresentados em relação à organização em que atuam, conforme observa-se no quadro 3.

Quadro 3- Caracterização dos casos e dos entrevistados

\begin{tabular}{|c|c|c|c|c|c|c|c|}
\hline $\begin{array}{l}\text { Caso } \\
\text { Código }\end{array}$ & $\begin{array}{c}\text { Entrevistados } \\
\text { Código }\end{array}$ & $\begin{array}{l}\text { Ano } \\
\text { Início }\end{array}$ & $\begin{array}{c}\text { Tamanho } \\
\text { Equipe }\end{array}$ & $\begin{array}{c}\text { Função ou } \\
\text { Cargo }\end{array}$ & Formação & Idade & Sexo \\
\hline OB1 & $\begin{array}{l}\text { Empreendedor } 1 \\
\text { EOB1 }\end{array}$ & 1997 & 18 & $\begin{array}{l}\text { Fundadora e } \\
\text { Diretora Exec. }\end{array}$ & $\begin{array}{l}\text { E. Superior/ } \\
\text { Doutora }\end{array}$ & 52 & $\mathrm{~F}$ \\
\hline OB2 & $\begin{array}{c}\text { Empreendedor2/ } \\
\text { EOB2 }\end{array}$ & 1992 & 16 & $\begin{array}{c}\text { Fundador } \\
\text { V.Presidente }\end{array}$ & $\begin{array}{l}\text { E. Superior } \\
\text { Doutor }\end{array}$ & 70 & M \\
\hline OB3 & $\begin{array}{c}\text { Empreendedor } 3 \\
\text { EOB3 }\end{array}$ & 2008 & 14 & $\begin{array}{l}\text { Fundador e } \\
\text { Diretor Exec, }\end{array}$ & E. Médio & 40 & M \\
\hline OP1 & $\begin{array}{l}\text { Empreendedor } 4 \\
\text { EOP1 }\end{array}$ & 2017 & 4 & Diretora Exec. & $\begin{array}{l}\text { E. Superior } \\
\text { Mestre }\end{array}$ & 37 & $\mathrm{~F}$ \\
\hline OP2 & $\begin{array}{l}\text { Empreendedor } 1 \\
\text { EOP2 }\end{array}$ & 2009 & 8 & $\begin{array}{l}\text { Fundadora e } \\
\text { Diretora Exec. }\end{array}$ & $\begin{array}{l}\text { E. Superior } \\
\text { Doutora }\end{array}$ & 47 & $\mathrm{~F}$ \\
\hline OP3 & $\begin{array}{c}\text { Empreendedor } 1 \\
\text { EOP3 }\end{array}$ & 2010 & 7 & $\begin{array}{l}\text { Fundador e } \\
\text { Diretor Exec. }\end{array}$ & $\begin{array}{l}\text { E. Superior } \\
\text { Mestre }\end{array}$ & 36 & M \\
\hline
\end{tabular}

Fonte: Dados da pesquisa.

O quadro 3 permite identificar que, os empreendedores sociais pesquisados em ambos os países, apresentam um perfil semelhante no que diz respeito ao nível educacional e cargo ocupacional. 0 efeito positivo do nível da formação encontrado corrobora o de outros estudos empíricos existentes, como os de Vieira (2017), Bosma et al. (2016), Bernardino (2013), que indica que a maioria dos empreendedores sociais tem formação superior. Isto sugere que a formação poderá aumentar a sensibilidade para as questões sociais e promover uma maior conscientização sobre a necessidade de atuar no campo social, isto pode ser interpretado como um preditor indireto para a criação de valor social. Com exceção do gênero que não apresentou diferenças significativas no quadro 3, formado por 3 homens e 3 mulheres, as demais variáveis identificadas podem sugerir contribuições positivas para a gestão das organizações que empreendem socialmente.

Quanto às principais diferenças entre encontradas entre os empreendedores sociais dos diferentes países, analisa-se a idade: os empreendedores sociais portugueses estão concentrados na faixa etária 


\section{Gestãoe \\ Desenvolvimento}

e-ISSN: 2446-6875

p-ISSN: $1807-5436$

mais jovem entre os 35 e 45 anos, ao contrário dos brasileiros que apresentam uma amplitude maior, que vai desde a faixa etária intermediária até a avançada (40 aos 70 anos). No grupo português, a atuação das duas mulheres à frente de organizações sociais corrobora os resultados do GEM (2019) e Marin et al. (2019), e mesmo que estes casos não sejam representativos quantitativamente, é possível sugerir que no contexto pesquisado em Portugal pode haver uma orientação social forte entre as mulheres. Assim, de modo geral, os dados relativos ao perfil dos empreendedores sociais deste estudo manifestam semelhanças com os dados do relatório do GEM Social (2016), British Council (2017), Pipe Social (2019) e GEM (2019). Dessa forma, a identificação do perfil demográfico dos empreendedores sociais brasileiros e portugueses pesquisados sugerem que há uma tendência em relação à predominância de escolaridade mais elevada e idade mais avançada, que podem influenciar de forma positiva os indivíduos que pretendem empreender socialmente.

Com relação às categorias analíticas dos valores pessoais, observou-se que a promoção do bem-estar de todos e a característica da humildade reflete-se no cotidiano dos entrevistados, sendo exemplificado pela fala de EOB3 e EOB2:

(...) É, na realidade eu tenho uma visão muito particular com relação a isso, né. (...) quando eu saio da empresa e vou pra casa eu não desligo. Tipo assim, não é: Ah, tô nem aí pra essa pessoa com deficiência (...) (EOB3).

(...) Exceto em algumas poucas ocasiões, eu prefiro não chamar atenção sobre mim mesmo. Eu, em algumas ocasiões é, vejo que preciso fazer isso, na hora que tá captando recurso principalmente, e aí tem que fazer, até porque eu acabei exercendo uma certa liderança, então tem horas que você tem que colocar o chapéu de líder e atuar, mas isso no dia a dia não é bom não (EOB2).

A análise dos tipos motivacionais identificados entre os empreendedores brasileiros pesquisados permitiu a apreensão de valores ilustrados na figura 1. A figura 1 diferencia os valores pessoais dos pesquisados, sendo escolhida a representação na cor azul para identificar aqueles que expressam interesses individuais, e vermelha para ilustrar os interesses coletivos, conforme ilustra-se na figura 1, a seguir. 


\section{Gestãoe \\ Desenvolvimento}

e-ISSN: 2446-6875

p-ISSN: 1807-5436

Figura 1 - Síntese dos valores pessoais presente nos pesquisados brasileiros

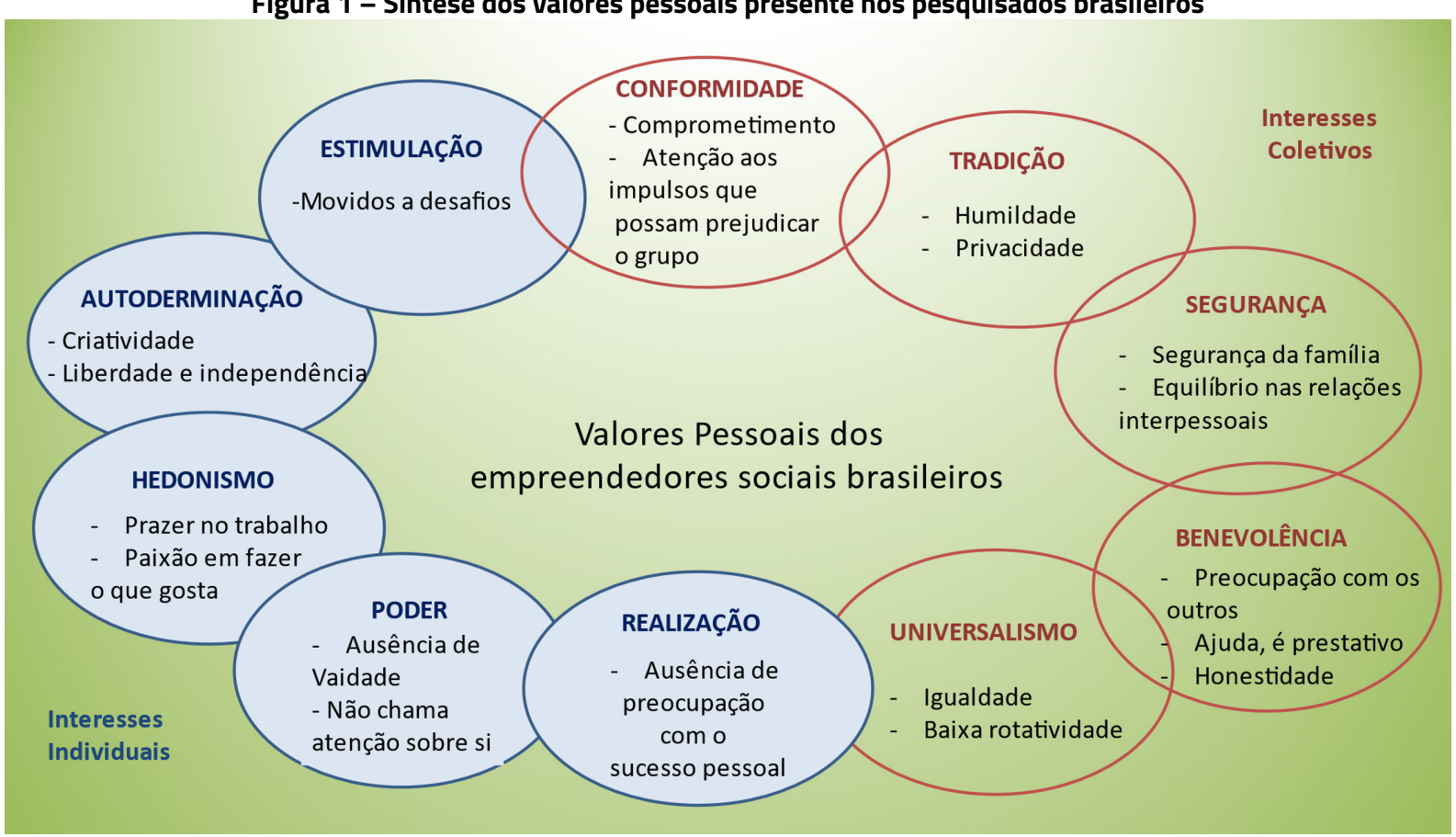

Fonte: Elaborado pelos autores com base nos dados da pesquisa.

Compreende-se, a partir da figura 1, que os pesquisados não são obcecados pela busca do êxito pessoal, pois não gostam de chamar atenção para si. As evidências sugerem uma ênfase maior para o lado da Autotranscendência (Universalismo e Benevolência), em oposição aos valores de autopromoção (ligados a poder e realização).

Entre os pesquisados portugueses, destaca-se que a benevolência também se manifesta, estando presente nos seguintes testemunhos:

(...) Tenho mais essa preocupação para com a equipe do que comigo (...). E é uma preocupação nossa que de facto a comunidade perceba o que fazemos e o valor que estamos a acrescentar. E depois também tem essa preocupação para que cada pessoa sinta a valorização daquilo que é o seu trabalho (EOP1).

(...) Eu tenho um problema grave. Preocupo-me muito mais com o bem-estar dos outros do que com o meu (...). Não é exemplo pra ninguém, mas é uma falha dos empreendedores sociais (EOP2). 


\section{Gestãoe \\ Desenvolvimento}

e-ISSN: 2446-6875

p-ISSN: $1807-5436$

As falas dos investigados portugueses sugerem ainda, que os pesquisados também possuem uma predominância de valores relacionados com interesses coletivos, marcado pela ênfase ao universalismo, conformidade, tradição, segurança e benevolência, conforme identifica-se na figura 2, a seguir.

Figura 2 - Síntese dos valores pessoais presente nos pesquisados portugueses

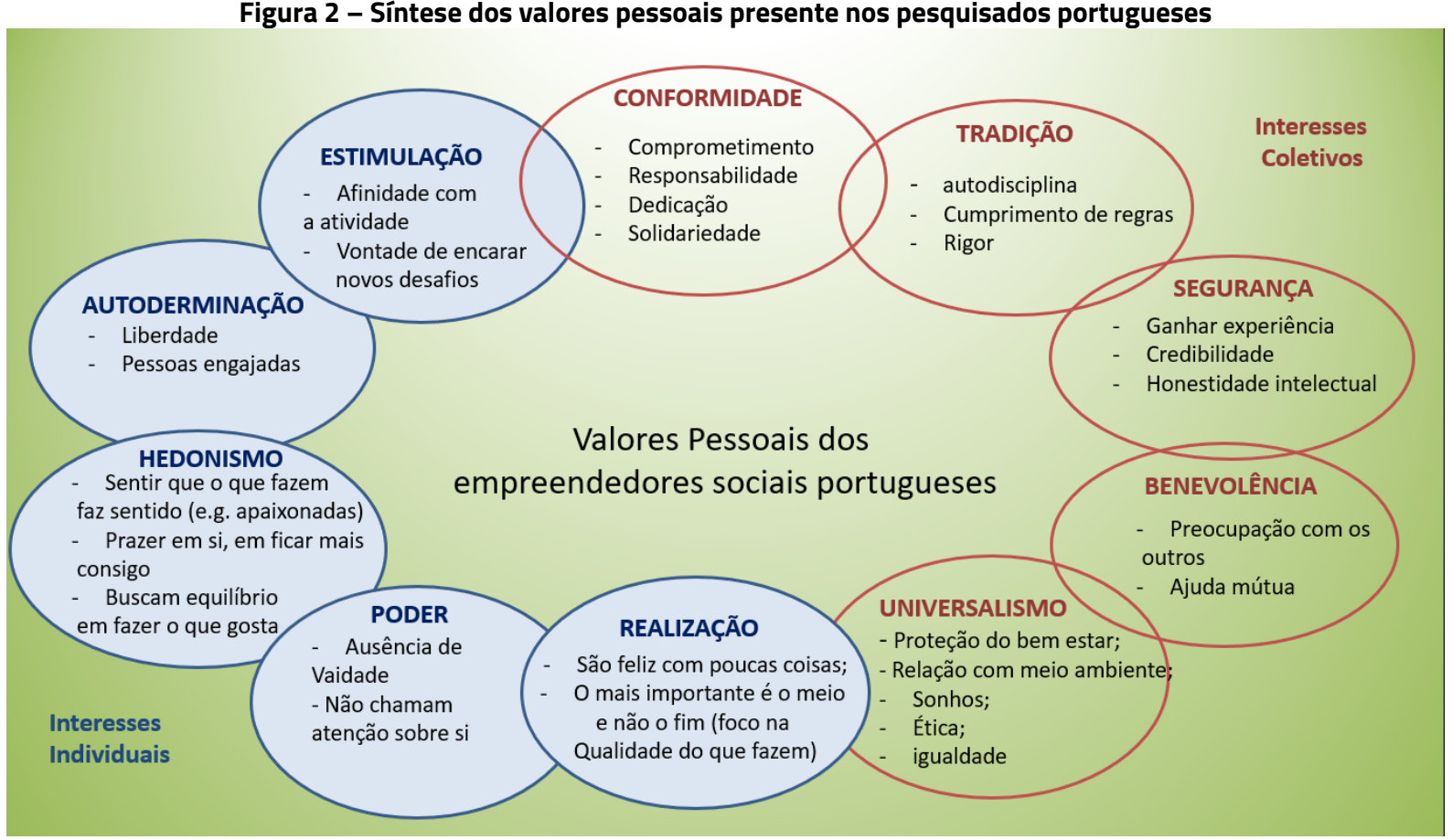

Fonte: Elaborado pelos autores com base nos dados da pesquisa.

Os fatores de conservação manifestados entre os pesquisados portugueses (Figura 3), que englobam a segurança, tradição e conformidade chamam atenção para uma análise que os aproxima dos interesses coletivos. Assim, a avaliação dos pesquisados indica a predominância de valores voltados para fatores de autotranscendência, característicos de uma comunidade voltada aos interesses do bem-estar dos outros, para a sobrevivência do grupo, com aceitação das diversidades entre os indivíduos.

Os pesquisados demonstram uma preocupação maior com o bem-estar das pessoas e com a coletividade, colocando os interesses coletivos à frente dos interesses individuais e isto corrobora a percepção de que há um elevado nível de altruísmo encontrado em empreendedores sociais que abdicam de ganhos pessoais em prol de ganhos para a coletividade.

Com relação às categorias analíticas das características dos empreendedores sociais o quadro 4 aponta as principais convergências e divergências entre as características dos pesquisados brasileiros 
e portugueses. Percebe-se que entre os pesquisados de ambos os países há forte similaridade entre as características, conforme elenca-se no quadro 4, a seguir.

Quadro 4 - Pontos convergentes e divergentes entre as características dos empreendedores sociais

\begin{tabular}{|c|c|c|}
\hline CARACTERÍSTICAS & PONTOS CONVERGENTES & PONTOS DIVERGENTES \\
\hline $\begin{array}{l}\text { Almejam criar valor } \\
\text { social, engajados com } \\
\text { foco no valor social e } \\
\text { missão social }\end{array}$ & $\begin{array}{l}\text { - Há construção de um projeto de vida } \\
\text { voltado ao empreendedorismo social; } \\
\text { - querem produzir mudanças e } \\
\text { transformar o mundo num lugar } \\
\text { melhor, por meio de acesso a maiores } \\
\text { oportunidades e possibilidades de } \\
\text { alavancar a economia; }\end{array}$ & $\begin{array}{l}\text {-Brasileiros manifestam atitude de inconformismo } \\
\text { frente às injustiças sociais (direitos civis } \\
\text { negligenciados pelo Estado); } \\
\text {-Portugueses manifestam objetivo de gerar } \\
\text { poupanças significativas às famílias dos usuários e } \\
\text { às finanças do governo português; }\end{array}$ \\
\hline $\begin{array}{l}\text { Inovadores, criativos, } \\
\text { buscam oportunidades }\end{array}$ & $\begin{array}{l}\text { - criam metodologias sociais e projetos } \\
\text { diferenciados; } \\
\text { - mobilizam a comunidade para a criação } \\
\text { e apoio aos projetos sociais; } \\
\text { - buscam investidores e parcerias } \\
\text { (privadas e públicas); } \\
\text { - atuam em diferentes territórios; }\end{array}$ & $\begin{array}{l}\text {-Brasileiros percebem o seu pioneirismo em relação } \\
\text { aos produtos e serviços criados; a maioria age em } \\
\text { territórios locais específicos; } \\
\text {-Portugueses manifestam rigor nas etapas da } \\
\text { elaboração de projetos piloto, bem como da } \\
\text { validação, a maioria possui visão de expansão para } \\
\text { outros países (territórios); }\end{array}$ \\
\hline Pro ativos & $\begin{array}{l}\text { - antecedem-se aos problemas futuros; } \\
\text { - demonstram capacidade de organização } \\
\text { e planejamento das ações; }\end{array}$ & $\begin{array}{l}\text { - Brasileiros pesquisados buscam recursos por } \\
\text { meio de seus gestores e capacitam a equipe para } \\
\text { buscarem recursos; } \\
\text { - Portugueses pesquisados estabelecem } \\
\text { relacionamentos de confiança com equipes e } \\
\text { parceiros, confiam nos seus parceiros; }\end{array}$ \\
\hline $\begin{array}{l}\text { Capacidade de assumir } \\
\text { riscos e capital }\end{array}$ & $\begin{array}{l}\text { - evitam dependência de investidores } \\
\text { únicos e estabelecem relações com } \\
\text { diferentes atores e parceiros; } \\
\text { - realizam a diversificação de recursos } \\
\text { e captam recursos junto a fundos de } \\
\text { investimentos público e privado; }\end{array}$ & $\begin{array}{l}\text { - Brasileiros pesquisados reconhecem dificuldades } \\
\text { quanto ao enfrentamento das barreiras da } \\
\text { burocracia e tributação; enfrentam a ausência de } \\
\text { fundos específicos; } \\
\text { - Portugueses pesquisados possuem acesso à } \\
\text { fundos específicos; }\end{array}$ \\
\hline $\begin{array}{l}\text { Habilidade com pessoas } \\
\text { (capital humano) }\end{array}$ & $\begin{array}{l}\text { - experiência profissional em empresas } \\
\text { púbicas ou privadas; experiência } \\
\text { de vida vinculada aos problemas } \\
\text { sociais; desenvolvem a autonomia e } \\
\text { comprometimento da equipe; há paixão } \\
\text { pela atividade; }\end{array}$ & $\begin{array}{l}\text {-Brasileiros não identificam a educação formal como } \\
\text { único meio de aprendizagem; } \\
\text { - Portugueses possuem foco na qualidade do } \\
\text { recrutamento da equipe e escolha dos projetos; }\end{array}$ \\
\hline $\begin{array}{c}\text { Sustentabilidade } \\
\text { (foco meio ambiente) }\end{array}$ & $\begin{array}{l}\text {-promovem } \\
\text { mobilização parçãa } \\
\text { desigualdades; projetos voltados para a } \\
\text { educação ambiental; }\end{array}$ & $\begin{array}{l}\text { - Brasileiros desenvolvem ações com impactos } \\
\text { diretos e indiretos; } \\
\text { - A maioria dos portugueses pesquisados percebem } \\
\text { que suas ações não possuem impacto direto; }\end{array}$ \\
\hline
\end{tabular}

Fonte: Elaborado pelos autores com base nos dados da pesquisa. 
No quadro 4, a adoção da inovação e da busca de oportunidades sociais são manifestadas pelos pesquisados de ambos os países, com relatos que convergem para a importância do estabelecimento de parcerias junto a órgãos públicos e privados. Dentre os aspectos divergentes agrupados no quadro 4, destacam-se a capacidade de assumir riscos e capital, na qual os brasileiros percebem que os recursos financeiros e o excesso de tributação acabam por dificultar a agilidade na tomada de suas decisões e dedicam-se a atuar em contextos locais, enquanto os portugueses demonstram visão de expansão de suas atividades para outros países. Com relação aos principais aspectos convergentes, cita-se a existência de indivíduos apaixonados pela missão social e pelas atividades que desempenham, assim como as experiências de vida que são caracterizadas pela humildade e pelo engajamento social.

Os pesquisados demonstram uma relação forte ao pôr em prática a missão social, pois possuem foco para o valor social e almejam criar valor social ao desenvolverem suas atividades com o propósito de transformação social (LEADBEATER, 1997; DEES, 2002; DRAYTON, 2002; MAIR; MARTI, 2006; BORNSTEIN; DAVIS, 2010). O altruísmo também é manifestado nos relatos dos entrevistados, sugerindo que os empreendedores sociais acabam deixando até mesmo em segundo plano as próprias vontades em prol do bem estar dos outros.

\section{CONSIDERAÇÕES FINAIS}

Fatores impostos pelo ambiente externo dos dois países, por exemplo em relação ao excesso de burocracia exigida no Brasil e à similaridade de legislação entre Portugal e os demais países da União Europeia, podem alavancar ou não a ampliação de impacto das organizações sociais. No Brasil, os pesquisados driblam o excesso de burocracia e da dificuldade da legislação que demandam metas conservadoras dos empreendedores sociais; a legislação de Portugal é similar à dos demais países que compõem a União Europeia, e isto pode representar oportunidades para que os pesquisados, por meio de suas atividades, consigam extrapolar o impacto social das suas organizações.

As evidências semelhantes obtidas sobre os valores pessoais dos pesquisados brasileiros e portugueses corroboram os estudos conduzidos com empreendedores sociais do Chile (BARGSTED et al., 2013) e da Grécia (SOTIROPOULOU et al., 2019). Em ambos os estudos desenvolvidos no Chile e na Grécia, os pesquisadores observaram que, juntamente com a autotranscendência, um dos valores mais importantes carregados pelos empreendedores sociais é a abertura às mudanças. Entre os pesquisados brasileiros e portugueses, destaca-se que a abertura às mudanças é percebida pela valorização da autodeterminação, na qual percebe-se a existência de uma forte orientação social para empreender, e 
esta orientação pode se aproximar do objetivo altruísta que está imbuído nos empreendedores sociais entrevistados.

Os resultados desta pesquisa sugerem que existe uma preocupação maior com o bem-estar do grupo do que com a realização individual, sugerindo assim que o motivo social dos brasileiros e portugueses empreenderem está pautado na característica do altruísmo. Este fato sugere a existência de uma aproximação entre as características dos empreendedores sociais e os valores pessoais, como também é defendido por Bargsted et al. (2013), corroborando a reflexão de que o empreendedor social apresenta um perfil com valores relacionados ao altruísmo.

Levando-se em consideração a existência de similaridades entre as características dos empreendedores sociais e comerciais, compreende-se que as diferenças do contexto social e tradicional, com comportamentos que, na maioria das vezes, são impulsionados pelo capitalismo, fortalecem as percepções sociais que podem implicar na adoção de estratégias com objetivo altruísta. Destaca-se que a cultura do altruísmo pode fortalecer ainda o sentimento de pensar no próximo, de forma a impulsionar as contribuições e trazer benefícios à sociedade.

Como principais contribuições da pesquisa, podem ser destacadas, em nível teórico, a possibilidade de ampliar a discussão conjunta sobre as temáticas dos valores pessoais relacionados às características dos empreendedores sociais. Em nivel prático, o entendimento do comportamento de organizações sociais do Brasil e de Portugal contribui para ampliar a discussão do comportamento organizacional, aplicado em cada um dos contextos, considerando as peculiaridades encontradas em cada país.

Destacam-se as limitações relacionadas ao método, já que o tempo disponibilizado por cada organização não permitiu o acesso a um número maior de investigados que pudessem validar as falas dos entrevistados (empreendedores sociais) e a vivência da pesquisadora por um maior período em cada contexto estudado. Por se tratar de um estudo com poucos casos, salienta-se a dificuldade de generalizações, cujos resultados obtidos restringem-se aos casos da realidade local estudada, baseada fundamentalmente na percepção do empreendedor social investigado. Como possibilidade de estudos futuros, sugere-se a inclusão de uma análise para compreender como o papel do governo, das parcerias, das empresas privadas, das universidades e demais ONGs podem contribuir com o desenvolvimento do empreendedorismo social, pois a cada novo estudo, há novas oportunidades que podem auxiliar a minimizar as complexidades existentes no campo do empreendedorismo social.

Como sinalização para uma futura investigação, reflete-se que, como esta pesquisa deteve-se apenas ao estudo de empreendedores sociais do Brasil e de Portugal, utilizando-se uma pesquisa de caráter qualitativo, seria interessante estender o modelo de investigação a outros contextos empíricos, adotando também o caráter quantitativo, de modo a contrastar os resultados obtidos e compreender 


\section{Gestãoe \\ Desenvolvimento}

e-ISSN: 2446-6875

p-ISSN: 1807-5436

até que ponto o comportamento das organizações e dos empreendedores sociais diferem entre países, possibilitando assim a abrangência e o aprofundamento do estudo.

\section{REFERÊNCIAS}

ANDE. Aspen Network of Development Entrepreneurs. Regional chapters. Mapping the impact investing sector in Brazil, 2014. Disponivel em: <https://assets.aspeninstitute.org/content/uploads/files/content/docs/pubs/ImpactInvestingStudy_FINAL_VERSION_ENGLISH.pdf1313273200.1563464417>. Acesso: 18 fev. 2018.

ASHTON, R. How to be a social entrepreneur, make money and change the world. Capstone: Chichester, 2010.

AUERSWALD, P. Creating social value. Stanford Social Innovation Review, p. 49-55, 2009.

AUSTIN, J.; STEVENSON, H.; WEI-SKILLERN, J. Social and Commercial Entrepreneurship: Same, Different, or Both? Entrepreneurship Theory and Practice, v. 30, n. 1, p. 1-22, 2006.

BANERJEE, R. P. Beyond human values: divine values for new era corporations. In: Ananda Das Gupta (Org.). Human Values in Management, p. 112-126, Aldershot: Ashgate, 2004.

BARDIN, L. Análise de conteúdo. Lisboa: Edições 70, 2015, 225 p.

BARENDSEN, L.; GARDNER, A. Is the social entrepreneur a new type of leader? Leader to leader, v. 34, n. 43-50, p. 2004.

BARGSTED, M.; PICON, M.; SALAZAR, A.; ROJAS, Y. Psychosocial Characterization of Social Entrepreneurs: A Comparative Study. Journal of social entrepreneurship. n. 4, p. 331-346, 2013.

BERNARDINO, S. J. Q. Iniciativas de empreendedorismo social no Terceiro Setor em Portugal: antecedentes, comportamentos e desempenho organizacionais. 2013. 414f. Tese (Doutorado em Ciências Econômicas e Empresariais) - Universidade Portucalense. Porto, 2013.

BHATTA, C. P. Effective leadership: human values perspective. In: Ananda Das Gupta (org.). Human Values in Management. Aldershot: Ashgate, p. 223-240, 2004.

BORNSTEIN, D.; DAVIS, S. Social entrepreneurship: what everyone needs to know. New York: Oxford University Press, 2010. 


\section{Gestãoe \\ Desenvolvimento}

e-ISSN: 2446-6875

p-ISSN: $1807-5436$

BOSMA, N. S.; SCHOTT, T.; TERJESEN, S.; KEW, P. Special Topic report on Social entrepreneurship. 2016. Babson College. Global Entrepreneurship Research Association. Disponivel em: <http://www.american.edu/kogod/auci/upload/SocialEntrepreneurshipWomenMenUS.pdf>. Acesso em: 02 ago. 2017.

BRITISH COUNCIL. O papel dos negócios sociais no apoio ao empoderamento feminino no Brasil. Relatório. British Council, 2017. Disponivel em: <https://www.britishcouncil.org.br/sites/default/files/negocios-sociais-empoderamento-feminino-brasil.pdf>. Acesso em: 25 ago. 2019.

CASAQUI, V. A construção do papel do empreendedor social: mundos possíveis, discurso e o espírito do capitalismo. Galáxia, São Paulo, [Online], n. 29, p. 44-56, jun, 2015. Disponível em: <http://www.scielo. br/pdf/gal/n29/1982-2553-gal-29-0044.pdf>. Acesso em: 22 jun. 2018.

COOK, B.; DODDS, C.; MITCHELL, W. Social entrepreneurship: false premises and dangerous forebodings. Centre of Full Employment and Equity CoFFEE. Working paper, 01-13. The University of Newcastle, Australia, 2001.

DACIN, P.; DACIN, M. E.; MATEAR, M. Social entrepreneurship: why we don't need a new theory and how we move forward from here. Academy of Management Perspectives, p. 38-57, 2010.

DACIN, T. M.; DACIN, P. A.; TRACEY, P. Social entrepreneurship: a critique and future directions. Organization Science, v. 22, n. 5, p. 1203-1213, 2011

DEES, J. G. Scaling social impact research project (1998). Annotated bibliography. Disponível em: <www.caseatduke.org/documents/scalingsocialimpact.pdf).2008>. Acesso em: 20 mar. 2016.

DEES, J. G. Taking Social Entrepreneurship Seriously. Society, v. 44, n. 3, p. 24-31, 2007. Disponível em: <https://centers.fuqua.duke.edu/case/wp content/uploads/sites/7/2015/02/Article_Dees 2007.pdf>. Acesso em: 02 out. 2017.

DRAYTON, W. The citizen sector: becoming as entrepreneurial and competitive as business. California Management Review, ISSN 0008-1256, v. 44, n. 3, p. 120-133, 2002.

EDMONDSON, A.; MCMANUS, S. Methodological fit in management field research. Academy of Management Review, v. 32, n. 4, p. 1155-1179, 2007.

ENGELMAN, R.; MENEZES, U. G.; ZINGANO, E.; POJO, S. Empreendedor social: análise com base na técnica laddering. Gestão e Desenvolvimento, ISSN: 2446-6875, v. 12, n. 2, p. 205-222, 2015.

FUNDAÇÃO SCHWAB. Schwab Foundation for Social Entrepreneurship. Social entrepreneurs and organizations. Disponivel em: <http://www.schwabfound.org/entrepreneurs>. Acesso em: 05 jan. 2018. 


\section{Gestãoe \\ Desenvolvimento}

e-ISSN: 2446-6875

p-ISSN: $1807-5436$

GEM SOCIAL. Global Entrepreneurship Monitor. 2015 to 2016. In: BOSMA, N. S.; SCHOTT, T.; TERJESEN, S.; KEW, P. Special Topic report on Social entrepreneurship. Babson College. Global Entrepreneurship Research Association, 2016. Disponivel em: <http://www.gemconsortium.org>. Acesso em: 05 jan. 2018.

GEM. Global Entrepreneurship Monitor. 2018 to 2019. In: BOSMA, N. S.; KELLEY, D. Report 2018 to 2019. Babson College. Global Entrepreneurship Research Association, 2019.

HAYWARD, M. L. A.; SHEPHERD, D. A.; GRIFFIN, D. S. A hubris theory of entrepreneurship. Management Science, v. 52, n. 2, p. 160-172, 2006.

HEMINGWAY, C. A. Personal values as catalyst for corporate social entrepreneurship. Journal of Business Ethics, v. 60, p. 233-249, 2005.

HOLT, D. H. A comparative study of values among Chinese and U.S. entrepreneurs: pragmatic convergence between contrasting cultures. Journal of Business Venturing, v. 12, p. 483-505, 1997.

KIRKLEY, W. W. Entrepreneurial behaviour: the role of values. International Journal of Entrepreneurial Behavior \& Research, v. 22, n. 3, p. 1-32, 2016.

LEADBEATER, C. The rise of the social entrepreneur. Demos: London, 1997.

LONDON, M.; MORFOPOULOS, R. G. Social entrepreneurhip: how to start successful corporate social responsability and community-based initiatives for advocacy and change. New York: Taylor \& Francis, 2010.

LÜDKE, M. ANDRÉ, M. E. D. A. Pesquisa em educação: abordagens qualitativas. São Paulo: EPU, 1986.

MAIR, J. E.; MARTÍ, I. Social entrepreneurship: a source of explanation, prediction and delight. Journal of World Business, v. 41, p. 36-44, 2006.

MARCONI, M. de A.; LAKATOS, E. M. Fundamentos de metodologia científica. 7. ed. São Paulo: Atlas, 2010.

MARIN, L; NICOLÁS, C.; RUBIO, A. How gender, age and education influence the entrepreneur's social orientation: the moderating effect of economic development. Sustainability, v. 11, n. 17, 2019.

MARTIN, R. L.; OSBERG, S. Social entrepreneurship: the case for definition. Stanford Social Innovation Review, p. 27-39, 2007. 


\section{Gestãoe \\ Desenvolvimento}

e-ISSN: 2446-6875

p-ISSN: $1807-5436$

MARTINS, G.; LINTZ, A. Guia para elaboração de monografias e trabalhos de conclusão de curso. São Paulo: Atlas, 2000.

MELLO, J. P. Negócios sociais em contexto brasileiro: contradições e potencialidades como alternativa econômica. 2016. 109 p. Dissertação (Mestrado em Administração, Programa de Pós-graduação em Administração) - Universidade Estadual de Londrina, UEL. Londrina, 2016.

MELO NETO, F. P. de; FROES, C. Empreendedorismo social: a transição para a sociedade sustentável. Rio de Janeiro: Qualitymark, 2002.

NICHOLLS, A.; CHO, A. H. Social entrepreneurship: the structuration of a fiel. In: NICHOLLS, A. (Org.). Social entrepreneurship: new models of sustainable social change. Oxford: Oxford University Press, p. 99118. 2008.

NICHOLLS, A. Social enterprise and social entrepreneurship. The Oxford Handbook of Civil Society, ed. M. Edwards. Oxford: OUP. p. 80-93. 2011.

OBSCHONKA, M.; SILBEREISEN, R.; SCHMITT-RODERMUND, E. Entrepreneurial intention as developmental outcome. Journal of Vocational Behavior, v. 77, n. 1, p. 63-72, 2010.

PARENTE, C. Empreendedorismo social em Portugal. Universidade do Porto: Porto, 2014. Disponível em: <http://ler.letras.up.pt/uploads/ficheiros/12386.pdf>. Acesso em: 25 jan. 2018.

PEREDO, A. M.; McLEAN, M. Social entrepreneurship: a critical review of the concept. Journal of World Business, n. 41, p. 56-56, 2006.

PIPE SOCIAL. $2^{\circ}$ Mapa de negócios de impacto social + ambiental. Relatório. Pipe Social, 2019. Disponível em: <https://pipe.social/mapa2019>. Acesso em: 25 ago. 2019.

ROUNDY, P. T. Social entrepreneurship and entrepreneurial ecosystems: complementary or disjoint phenomena? International Journal of Social Economics, v. 44, n. 9, p. 1252-1267, 2017. Disponível em: <https://doi.org/10.1108/IJSE-02-2016-0045>. Acesso em: 15 abr. 2019.

SCHWARTZ, S. H. A proposal for measuring value orientations across nations. In: Questionnaire Development Package of the European Social Survey, chapter 7, p. 259-319, 2003. Disponivel em: <http:// www.europeansocialsurvey.org/index.php?option_com_docman\&task_doc_view\&gid_126\&ltemid_80>. Acesso em: 05 jan. 2018.

SCHWARTZ, S. H. A theory of cultural values and some implications for work. Applied Phychology: an international review, v. 48, n. 1, p. 23-46, jan./mar. 2003. 


\section{Gestãoe \\ Desenvolvimento}

e-ISSN: 2446-6875

p-ISSN: $1807-5436$

SCHWARTZ, S. H. Há aspectos universais na estrutura e no conteúdo dos valores humanos? In: ROS, M.; GOUVEIA, V. V. (Orgs). Psicologia social dos valores humanos: desenvolvimentos teóricos, metodológicos e aplicados. São Paulo: Senac, 2006.

SCHWARTZ, S. H. Universals in the content and structure of values: theoretical advances and empirical tets in 20 countries. In: ZANNA, M. P. (Orgs.). Advances in experimental social psychology. Orlando, FL: Academic, v. 25, p. 1-65, 1992.

SCHWARTZ, S. H.; BLISKY, W. Toward a universal structure of human values. Journal of Personality and Social Psychology, v. 53, n. 3, p. 550-562, 1987.

SHAW, E.; CARTER, S. Social entrepreneurship: theoretical antecedents and empirical analysis of entrepreneurial processes and outcomes. Journal of Small Business and Enterprise Development, v. 14, n. 3, p. $418-434,2007$.

SOTIROPOULOU, A. PAPADIMITRIOU, D.; MAROUDAS, L. Personal Values and Typologies of Social Entrepreneurs. The Case of Greece. Journal of Social Entrepreneurship, 2019. doi: https://doi.org/10.1080 /19420676.2019.1668827.

STEINEROWSKI, A.; JACK, S.; FARMER, J. Who are the social entrepreneurs and what do they actually do? Frontiers of Entrepreneurship Research, Babson College Entrepreneurship Research Conference (BCERC ). Journal of Social Entrepreneurship, v. 28, n. 21, artigo 2, 2008.

VIEIRA, N. S. Inovação social e desenvolvimento de competências em organizações da sociedade civil sem fins lucrativos brasileiras e portuguesas. 2017. 363 p. Tese (Doutorado em Administração) - Universidade Federal de Minas Gerais, UFMG. Belo Horizonte 2017.

ZHARA, S. A.; GEDAJLOVIC, E.; NEUBAUM, D. O.; SHULMAN, J. M. A typology of social entrepreneurs: motives, search processes and ethical challenges. Journal of Business Venturing, v. 24. 2009.

ZAHRA, S. A.; WRIGHT, M.; ABDELGAWAD, S. G. Contextualization and the advancement of entrepreneurship research. International Small Business Journal, v. 32, n. 5, p. 479-500, 2014.

YIN, R. K. Pesquisa qualitativa do início ao fim. Porto Alegre: Penso, 2016. 